\title{
10 Rumors during organizational change: a motivational analysis
}

\section{Prashant Bordia and Nicholas DiFonzo}

Rumors play an important role in most, if not all, aspects of employee experience and responses to organizational change (DiFonzo and Bordia, 2006, 2007a). Take the example of readiness for change, a vital precursor to successful implementation of change (Jones, Jimmieson, and Griffiths, 2005). Readiness for change comprises employees' acceptance of the need for change and confidence (or efficacy) in their ability to carry out tasks needed for the change (Armenakis, Harris, and Mossholder, 1993). Rumors that allege illegitimate motivations for change can undermine the need for change. Similarly, rumors that allege incompetence-of-change managers can undermine efficacy beliefs. Because they materially affect the construction of the social reality of any organizational change, rumors are critically important aspects of change.

The aim of this chapter is to review the psychological research on rumors and apply it to the context of organizational change using a motivational framework to explain why rumors arise and spread during organizational change. A motivational framework has several advantages: first, it draws attention to the functional nature of rumors - that is, rumors spread because they fulfill certain psychological needs; second, the motivational approach provides an integrative framework for the variety of variables affecting rumor spread that have been identified in the literature (such as uncertainty, anxiety, outcome-relevant involvement, and belief in the rumor; Rosnow, 1991) and draws attention to as yet unexamined variables, such as threat to psychological esteem; third, our framework shows how the psychological experience of change triggers the motivations responsible for rumors, therefore the motivational approach helps us explicitly link organizational change and rumors; finally, a motivational approach offers insights into the management of rumors during change - effective management of rumors requires addressing the underlying motivations in rumor spread.

The broad conceptual framework guiding this chapter is presented in Figure 10.1. The psychological context of organizational change is marked by uncertainty and threat to tangible and intangible resources (sense of belonging and self-esteem); this context activates motivations related to 
Contextual Influences: Network Structure \& Organizational Trust

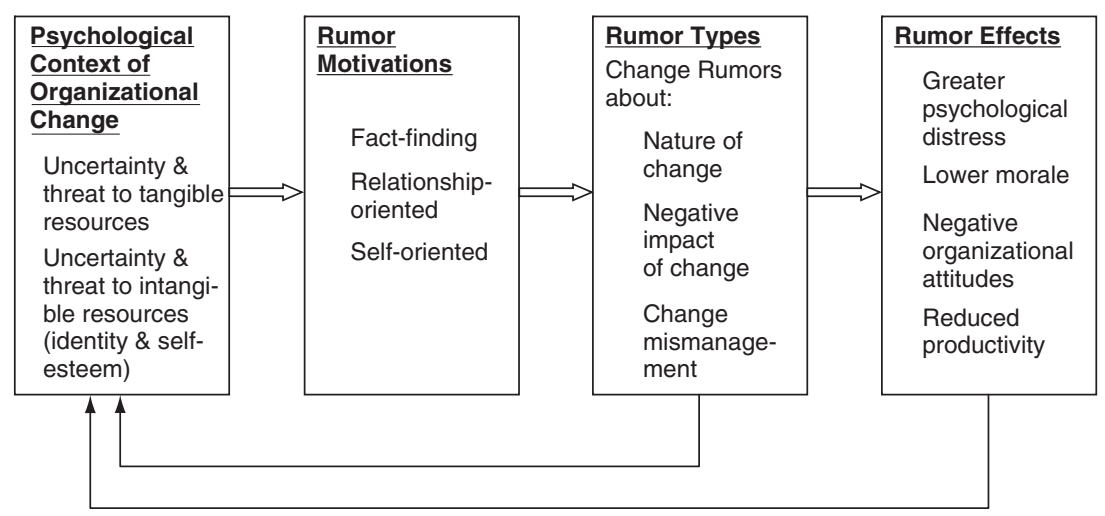

Figure 10.1 Motivational framework for rumors during organizational change

fact-finding, relationship-, and self-oriented goals and these motivations spur rumor activity. Using this motivational framework, we: (a) review the psychological literature on factors affecting rumor spread; (b) describe the types of rumors during change; (c) note the effects of rumors for employee outcomes during change; (d) outline the contextual effects of network structures and trust; and (e) propose implications of the motivational framework for rumor accuracy and management of rumor activity during organizational change. But first, we begin by defining rumor.

\section{Rumor defined}

Rumors are "information statements that circulate among people, are instrumentally relevant, and are unverified" (DiFonzo and Bordia, 2007a, 16). First, rumors are not merely personal thoughts, but are very much collective enterprises (Fine and DiFonzo, 2011). Second, rumors are meaningful statements that aim to inform and typically comprise a subject and a verb (e.g., "our jobs will be outsourced"). They are different from expressions of opinions ("I hate the changes in this organization") or expressions of cynicism ("haven't we been through these changes before?") but may accompany such conversations; indeed, rumors may create negative opinion or cynicism about change or justify existing opinion ("see, I was right in resisting the change, I hear that as part of the restructuring, our jobs will be outsourced"). The central defining feature of rumors is that they are unverified (i.e., they are not accompanied by secure evidence that 
would signify veracity; Allport and Postman, 1947). This does not mean that a rumor is false, it may indeed be true but still lack the accompanying substantiation or imprimatur demonstrating authenticity. Statements published in a reputable newspaper, for example, signify that a reporter has (presumably) checked the facts of the story; news is therefore typically thought of as information claim that has been properly tested, especially as contrasted with rumor.

\section{Rumors and the organizational change context}

There are several aspects of the organizational change context that are relevant to our understanding of rumors. To begin with, organizational change and the associated uncertainty are stressful for employees (Bordia et al., 2004). Uncertainty (or the lack of knowledge or predictability of one's circumstances; DiFonzo and Bordia, 1998) leads to feeling of lack of control, which in turn leads to an experience of stress. A variety of types of uncertainty have been identified (Schweiger and DeNisi, 1991), with Bordia et al. (2004) noting that these coalesce around three main foci: job related, which refers to uncertainty about job issues, such as job security and job demands; structural, or the uncertainty about the changes to functions and reporting structures of work units; and strategic uncertainty, which is uncertainty about the overall strategic direction of the changing organization. The effects of the structural and strategic uncertainty on feelings of lack of control flow through job-related uncertainty as job-related concerns tend to preoccupy employees (Bordia et al., 2004). While change agents may have the big picture in mind, and may think of the overall organizational context, change recipients are more focused on the relevance and impact of change for their personal circumstances, such as whether the change will affect their job role, responsibilities, or rewards (Bartunek et al., 2006).

Another major source of stress during organizational change is the threat of loss of tangible and intangible resources (Fugate, Prussia, and Kinicki, 2012). Resources (Hobfoll, 2002) refer to objects (e.g., equipment) or situational (e.g., social support) and personal (e.g., skills) characteristics that are required to meet demands placed on us (e.g., meeting deadlines at work). As noted by the conservation of resources (COR) theory, we are motivated to conserve resources and we find situations that deplete or threaten resources as stressful (Grandey and Cropanzano, 1999; Hobfoll, 2002). At a tangible level, if not an outright loss of job, organizational change can lead to loss of cherished work roles and outcomes such as status and rewards and an increase in undesirable aspects, such as skill obsolescence and retraining or an increase in workload. 
At an intangible level, change can drain psychological resources as it results in feelings of unworthiness stemming from the need to acknowledge mistakes or limitations. Change can threaten employee self-esteem in several ways. In Lewin's (1951) stages of change (unfreezing, change, and refreezing), the first step of unfreezing involves an acceptance that there is something wrong in the way things are currently operating in the organization (Weick and Quinn, 1999). For the employee, this can be a threatening experience because "if we admit to ourselves and others that something is wrong or imperfect, we will lose our effectiveness, our self-esteem, and maybe even our identity" (Schein, 1996, 29). Change can imply a weakness at the level of individual employee performance (inadequate levels of sales or customer satisfaction) and therefore undermine self-esteem. Change may also imply a failure or limitation at the organizational level. This would undermine the part of employee esteem derived from membership in valued groups, also referred to as the social identity (Ashforth and Mael, 1989). Finally, if change is poorly managed, it can result in perceptions of unfairness. As noted by the group value model (Tyler, Degoey, and Smith, 1996), unfair treatment can be perceived by employees as lack of respect from the organization which can instill feelings of being unwanted by the organization.

For the reasons outlined above, change imposes significant coping demands on employees (see Chapter 5 in this volume). One of the ways in which employees react to the uncertainty and threat of resource depletion is by acquiring additional resources or defending (conserving) existing resources. A key resource that helps employees understand and cope with the change is a better understanding of the nature and consequences of the change (Jimmieson, Terry, and Callan, 2004). This increased understanding - achieved via sense making - enhances interpretive and predictive control of the environment (Rothbaum, Weisz, and Snyder, 1982).

The sense making has a social element (Bordia and DiFonzo, 2004); employees seek and share information with others at work, including managers, union officials, and coworkers. The goal of the formal communication mechanism is to aid the sense making by providing adequate levels of information to employees. In reality, however, the formal communication process is often inadequate or not trusted by the employees (DiFonzo and Bordia, 1998). As a result, the collective sense making includes the informal channels, also referred to as the grapevine. Rumors arise from this informal collective sense-making activity (Bordia and DiFonzo, 2004; DiFonzo and Bordia, 2007a; Shibutani, 1966). The rumor content is influenced by the need to make sense of the changing work environment (i.e., uncertainty reduction) as well as to cope with the threats to identity and self-esteem. As noted by Elsbach and Kramer (1996), identity threat 
triggers sense making, but this sense making involves strategies and explanations that defend the identity by rejecting the source of threat or questioning the validity of information that threatens the identity. In the context of organizational change, rumors provide alternate attributions for change and help reject the notion that change was necessitated by an underlying problem with the organization because accepting the latter would be threatening to one's identity and self-esteem.

Another aspect of organizational change that is relevant to our understanding of rumors is that communication is central to successful change in organizations. The importance of communication processes in change was reinforced by Ford and Ford (1995) who shifted the approach to the study of change communication from a "communication as a change-facilitating mechanism" to communication as the central vehicle by which change is achieved. According to them, change-related conversations are the means by which change is initiated, understood, implemented, and outcomes achieved. They presented four key elements of an idealized change conversation: (a) initiative conversation proposes the change, (b) understanding conversation clarifies the proposed change and develops achievement standards and targets, (c) performance conversation involves the precise implementation steps, and finally (d) closure conversation signals the end of the change program, and sums up the lessons learned and achievements derived from the change. In reality, however, the change conversation can get "distracted" at various stages, such as when the initiative is not accepted or when there are gaps in understanding between the proposed change and the one deduced by the participants. Rumors can be conceived of as a parallel conversation (or background conversation; Ford, Ford, and McNamara, 2002) that occurs in the informal organizational discourse. The rumors can propose alternate nature and aims of the change, a different understanding of the implementation steps and performance standards, and a divergent assessment of goals achieved.

Having outlined the context of organizational change from the employees' perspective, we now turn to understanding the factors that affect rumor spread. In the next section, we introduce the motivations that are activated by the uncertainty and threat posed by organizational change; using this motivational framework we then review the literature on factors affecting rumor spread.

\section{Psychological motivations in rumor spread during change}

The uncertainty and threat to tangible and intangible resources inherent in organizational change activate several core motivational goals that 
underlie social activity, including the goals of acting effectively, building and maintaining relationships, and enhancing one's sense of self (Cialdini and Trost, 1998; Wood, 2000). Acting effectively refers to successful environmental coping, that is, surviving and thriving in the social and physical world. To act effectively, we need information, feedback, and guidance from our social world; this need therefore leads to fact-finding motivations. Second, building and maintaining relationships is an adaptive need for humans as social animals. To build and maintain relationships, we act in ways that enhance social ties, including complying with requests, ingratiating others, and acting in a polite manner (Leary, 1995); this need therefore leads to relationship-oriented motivations. Finally, enhancing one's sense of self refers to the need to have a positive view of self and enhance our self-esteem (Alicke and Sedikides, 2009); this need leads to self-oriented motivations. Fact-finding, relationshiporiented, and self-oriented motivations all play a role in rumor spread. They are motivational in the sense that they represent core needs that humans seek to fulfill; these needs energize and direct rumor behavior (Pinder, 1984).

Rumors and fact-finding motives Considerable research evidence exists for the fact-finding motivation in rumor spread. Rumors abound during times of uncertainty about topics of high personal relevance (Rosnow, 1991). Faced with uncertainty and unsure about how to act or cope results in feelings of lack of control and anxiety (Bordia et al., 2004). People prefer to understand, predict, and control their environments (Fiske, 2004), and so when events are unexplained, meanings are unclear, and futures are unpredictable, they circulate speculative hypotheses in an attempt to procure explanation, prediction, and control (DiFonzo et al., 2012). Rumors are a product of this collective sense making.

Early evidence for the role of uncertainty in rumor spread was provided by Schachter and Burdick (1955). They first planted a rumor among several students in a girls' preparatory school by implying that someone had stolen examinations. Later, they manipulated uncertainty by either staging (or not) an event that produced great uncertainty (suddenly interrupting a class and withdrawing a girl without explanation: "Miss K... please come with me"; 365). Rumor transmission was nearly twice the rate in the high uncertainty group (those exposed to the staged event) compared to the low uncertainty group (those not exposed to the staged event). The process of rumor as group sense making has been demonstrated in Bordia and DiFonzo's (2004) analysis of rumor interactions on the Internet. They analyzed the content of rumor interactions and found a variety of 
statements reflecting collective problem solving, including statements asking for and providing information, interpreting and evaluating information, and concluding belief or disbelief in the rumor.

The effects of anxiety and uncertainty on rumor spread were strikingly visible in our study of rumors during large-scale downsizing in a division of a manufacturing organization (DiFonzo and Bordia, 2007a, ch. 2). The division downsized employee numbers by 50 percent. We surveyed employees over four time points. Time 1 (T1) and Time 2 (T2) were before the downsizing had been announced; however, restructuring of the departments had begun. Uncertainty and anxiety over the past month were measured using multi-item Likert-type scales (an example uncertainty item is "I was uncertain about whether I will be laid off" and an example anxiety item is "I felt anxious about possible changes that will occur in this company"). We also asked for the number of rumors they had heard in the past month and of these, the number of rumors they had passed on. We calculated the proportion of heard rumors that were passed on and termed this likelihood of transmission (LOT). T1 was marked by a variety of change-related activity in the organization and levels of uncertainty and anxiety were high. Uncertainty and anxiety peaked at T2, just prior to the layoff announcement, then reduced at T3 and reduced further at T4 (the layoffs occurred between T3 and T4). As predicted, anxiety and uncertainty were positively related to LOT at each time point as well as across time periods.

Rumors and relationship-oriented motives A second set of motivations consist of aims related to the teller-listener relationship: tellers take their "audience" into consideration when forming message content and delivery. Perhaps the most elementary of these is the desire that the idea be comprehensible to the listener (Ruscher, 2001). Tellers alter tales that would seem especially jumbled, implausible, or non-stereotypical so as to be more coherent, believable, and conventional to the hearer (Lyons and Kashima, 2006).

Tellers are also routinely motivated to enhance the relationship, a predilection owing to our basic human striving to belong (Fiske, 2004). Gauging the impact of a message on the teller-listener relationship necessitates consideration of the conversational context in which rumors are shared. A speaker is likely to take into account the affective tone of the conversation (Heath, 1996) and the characteristics of the audience (e.g., ingroup or outgroup member) in deciding whether or not to share a rumor. Tellers are more likely to communicate a rumor if hearing it is likely to reduce/avoid negative, or produce positive, affect in the recipient. With regard to negative affect, Tesser and Rosen (1975) in their classic work noted the "minimize 
unpleasant messages" (MUM) effect. According to the MUM effect, a speaker is likely to withhold negative information so as not to pay the price of being the bearer of bad news. Kamins, Folkes, and Perner (1997) demonstrated MUM effect in the rumor context. Compared to a rumor that their school was going to fall in next year's business school rankings, students were more willing to transmit a rumor that their school was going to rise in the rankings. In a recent extension of this study (DiFonzo and Bordia, 2007a, ch. 3), students asked to imagine themselves among outgroup members and presented with similar "your school ranking rose" (i.e., outgroup-positive) and "your school ranking fell" (i.e., outgroup-negative) rumors were more likely to share outgroup-positive rumors; this effect was indeed mediated by relationship-enhancement motivation. In other words, the desire to generate liking for the teller guided which rumors the teller was most likely to transmit.

Consideration of short-term effects on hearer affect and liking is powerful, but these may be overridden for longer-term pro-social aims. In this vein, Weenig, Groenenboom, and Wilke (2001) wondered why negative rumors abound if the MUM effect always operated. Their research showed that people were willing to share even bad or negative information with a friend (but not a casual acquaintance) if it is likely to be useful information. Such pro-social motivations explain the role of rumors as forewarnings. Rumors of job loss - even though anxiety provoking - are shared to warn coworkers of the likely impact of change.

More generally reflective of the teller's desire to belong (Baumeister and Leary, 1995), groups exert conformity pressures to accept some rumors while rejecting others (Åckerström, 1988). All other things being equal, rumors that fit well with accepted attitudes, cultural norms, and normative beliefs are better candidates for transmission than those that fit poorly (Allport and Postman, 1947; Prasad, 1950). The pressure to share a rumor that expresses a socially appropriate sentiment (e.g., "Management are aliens!") and to refrain from sharing a disquieting one can be very powerful (Baumeister and Hastings, 1997; DiFonzo, 2008). Paradoxically, the desire to belong also at the same time tempers these tendencies because of the social norm of telling the truth (Grice, 1975). This explains the finding that belief in the rumor is positively related to transmission (Rosnow, 1991). In longterm relationships and among established communication grapevines (common in workplace settings), one's reputation as a reliable and credible source of information is dependent on the accuracy of information one brings to the group (Caplow, 1947). Thus people are unlikely to threaten their reputation by sharing rumors that they themselves do not believe (DiFonzo and Bordia, 2002b). 
Rumors and self-oriented motives Because much of our sense of self is wrapped up in our social identity, self-oriented rumors - spread to achieve aims related to the teller as an individual - are often complementary to relationship-oriented ones (Bordia and DiFonzo, 2005). We retain this distinction however because social and self-orientations are often meaningfully contradistinguished, such as when a leader's sense of power is either of the socialized or personalized variety (Chusmir, 1986; McClelland and Burnham, 1976), or when pro-social acts are motivated by altruistic versus egoistic ends (Batson, Ahmad, and Stocks, 2011). "Relationship-orientation" thus conveys a focus on group/community whereas "self-orientation" connotes a relatively stronger egoism.

Most innocuous of the self-oriented aims are wish-fulfilment motives that drive the telling of tales that express the teller's hopes and wishes, such as when GM employees in the Ypsilanti, MI, plant scheduled for shutdown in 1993 heard false hearsay that the workers were buying the plant (Rimer, 1992). Such rumors are aptly named wish rumors (Knapp, 1944). Self-oriented motives also include more plainly self-enhancing desires to gain or maintain the prestige inherent in being someone "in the know" (Turner and Killian, 1972). Self-oriented rumors also include those spread to achieve cognitive consonance, that is, to reinforce the teller's own assumptions, axioms, and beliefs (Allport and Postman, 1947; Prasad, 1950). Cognitive consonance is the "cooler" analog to the more emotional aim of cognitive dissonance reduction (Festinger, 1957). These rumors are driven by a need to lessen the aversive psychological tension between conflicting thoughts or actions, as when a manager who considers herself a good decision maker continues to invest in a failing course of action (Ross and Staw, 1993; Staw, 1981); in this example, rumors of incipient success dilute the dissonant cognition.

Closely related to these are rumors spread for defensive motives to protect, regain or enhance one's sense of self, especially if it has been recently depleted (Baumeister, Smart, and Boden, 1996). This can be done using positive rumors about ourselves or our group, or negative rumors about others or their group, but there is some evidence that positive ingroup statements are more easily believed (Brewer, 2003). Positive rumors that our personnel are intelligent, our products are flawless, or our services are highly ethical are alluring in that they can well boost our self-image. In team decision-making settings such rumors may foster a sense of superiority inherent in the well-known dynamics of groupthink (Janis, 1972). Negative rumor at times also becomes a tool to boost one's sense of self, even at the cost of others' reputations. This phenomenon is most visible in the large number of rumors circulating at any given time that derogate an outgroup (also referred to as wedge-driving rumors; Knapp, 1944). These 
rumors justify our anxiety and give voice to our mistrust, or in the words of Allport and Postman (1947, 37), "rumor rationalizes while it relieves." For example, in addition to serving dissonance reduction functions about our own lackluster performance (e.g., "We have the best product, yet our market share is falling"), rumors that derogate the competition's products, services, or ethics (e.g., "I heard that our competitors succeed by bribery") indirectly boost our perception of our own organization's standing and by association our individual sense of worth.

More egregious uses of rumors include those wielded for revenge, that is, to exact a toll from those who have offended us (Bordia, Restubog, and Tang, 2008). After a psychological contract breach in an organizational context, offended employees are much more likely to spread a derogatory rumor about management than in non-breach conditions, and this effect is mediated by revenge cognitions (Bordia et al., 2011). Perhaps most questionable are rumors spread for considered strategic gain (Allport and Postman, 1947; Kapferer, 1990; Pratkanis and Aronson, 2001). Such propaganda rumors have been used to steer consumers away from rival products and toward one's own products, or to sabotage other ideas under consideration by management (DiFonzo and Bordia, 2007b).

\section{Types of rumors during organizational change}

The sense-making and threat-management functions of rumor were visible in a study that sought to identify the different types of rumors that circulate during organizational change. Bordia et al. (2006) surveyed employees of a large public hospital in Australia that was undergoing major changes to organizational structure and operational procedures as well as relocating to a new building. All 3,200 employees were sent paper and pencil surveys asking among other questions to report the last rumor they had heard about the changes in the organization. Over 1,600 surveys were returned, and of these, 776 respondents provided an answer to the rumor question. These responses were analyzed using a coding scheme developed inductively from the responses. The categories of rumors reflected the change-related sense making and threat management previously noted in the literature, including conjectures about the nature of change, impact of change, and whether the actions of the change agents match the stated process and goals (Bartunek et al., 2006). Nearly half the rumors reported were about the consequences of the change at the job level, including rumors predicting job losses, negative consequences for career advancement, negative changes to the type of work, and loss of job facilities. 
The second largest type of rumor was about the "true" or real nature of the change. These were highly specific descriptions and predictions of the departments that may merge and how the organization will restructure and look at the completion of the change program (e.g., "the new hospital will be a private hospital"). These two categories of rumor served the uncertainty management function by attempting to clarify the nature and consequences of change. We also found evidence of rumors that appeared to serve defensive motivations by derogating the change implementers and proposing non-performance-related reasons for change. Thus, the third most frequent set of rumors alleged poor and incompetent change management including wastage, misplaced priorities, and cynicism about reasons for change and the consultation process. The final two types of rumors included those that predicted (largely negative) consequences of the change for organizational performance and a few gossip-rumors, so labeled because they derogated individuals, such as the CEO or the unit manager, but pertained largely to their work roles.

\section{Effects of rumors during change}

Rumors have a variety of consequences. A survey of highly experienced public relations and corporate communication executives revealed that the most frequent negative effects (experienced by more than 90 percent of the sample) included lowered employee morale, bad publicity in the press, loss of trust between management and staff and among coworkers, and decreased productivity (DiFonzo and Bordia, 2000). In one case described by a respondent, rumor that two manufacturing plants were to close led to lowered morale and loss of productivity by 10 percent. It is also important to remember that rumors of planned or unplanned organizational change (such as forced mergers, restructuring, and insolvency) have internal (staff attitudes and behavior) as well as external effects such as changes to stock prices, bad press, and reputational damage.

In the downsizing study outlined above, we found employee attitudes such as job satisfaction, organizational commitment, and trust in the company to be negatively, and turnover intentions to be positively, related to hearing negative rumors (DiFonzo and Bordia, 2007a, ch. 2; note that, given the interactive nature of rumor spread, the effects are likely to be experienced by both the tellers and listeners as these roles interchange over the course of the spread of a rumor). These negative effects can be explained by social information processing theory (Salancik and Pfeffer, 1978); the negative rumors convey to employees that the organization is an undesirable place to work. Moreover, based on equity theory (Adams, 
1965), employees are unlikely to want to contribute or remain part of an organization that is marked by uncaring management practices (Bluedorn, 1982; Moorman, 1991). We further found that the cumulative effect of hearing rumors over several months was stronger than the effect of hearing rumors for a given month alone, suggesting that the possibility of a nonlinear relationship between hearing negative rumors and exhibiting negative attitudes and withdrawal behaviors.

Uncertainty and anxiety drive employees to seek relief through grapevine interaction. However, participating in the grapevine activity does not seem to reduce uncertainty and anxiety; on the contrary, hearing rumors at $\mathrm{T} 1$ was positively related to uncertainty and anxiety at $\mathrm{T} 2$. Either the rumors did not adequately address the uncertainty or they raised further questions and concerns about the nature of changes in the organization. A similar reciprocal relationship between rumors and psychological distress was found in our study of rumor types during organizational change (Bordia et al., 2006). In addition to rumors, the survey asked respondents to report change-related stress (on a 6-point bipolar scale ranging from not at all stressful to extremely stressful). As predicted, those who reported negative rumors also experienced greater change-related stress than those who reported positive or no rumors.

Rumors have consequences even when they may not be believed as people adopt a "better safe than sorry" approach. As noted by prospect theory (Kahneman and Tversky, 1979), people are more sensitive to losses than they are to gains. Indeed, people process negative information more than positive information and therefore overestimate the likelihood of negative events (Baumeister et al., 2001) and prefer to adopt a defensive strategy, just in case the rumors turn out to be true. In such circumstances, those rebutting the rumor may face an especially difficult task ahead of them trying to stop people from acting on the rumor.

\section{Contextual influences on rumor spread during organizational change}

Several context factors influence the rumor process. Network structure and trust are two understudied contextual variables of special note because they are likely to be theoretically important (DiFonzo and Bordia, 2007a, ch. 8; 2007b). Both variables refer to especially relational or social approaches of rumor transmission, approaches that were initially appreciated in rumor research, but fell out of favor with the ascendance of the twentieth-century psychological zeitgeist of the person-level unit of analysis (Bordia and DiFonzo, 2002). 
Network structure To say that rumor is a collective enterprise begs an important question: which collective? The question points toward the oft-overlooked fact of social life that persons are embedded within structured social networks, the nature of which may greatly impact the composition of the person's local collective, and thus the sense that is collectively construed and threat that is collectively managed. Network structure refers to the pattern or arrangement of relationships between persons in a network (Scott, 2000). In clustered network structures, densely connected sets of persons predominate so that the people one knows tend also to know one another, but not members of other clusters (Wasserman and Faust, 1994). Tribes, clans, and families are sociological examples of clustered structures; in organizations, examples of clustered networks include management circles, formal organizational divisions or departments, informal friendship networks, and communication grapevines (Rogers and Agarwala-Rogers, 1976).

Network structure first of all has consequences for where particular rumors spread, and this in turn affects the degree to which perceptions (e.g., about change) diverge. Rumors in general tend to circulate within densely connected network clusters - such as friendship networks (Festinger et al., 1948) and military units (Caplow, 1947), rather than between them. This is because of the predominance of within-cluster contacts (as compared to between-cluster connections) afforded by a highly clustered network, but also often because of motivational considerations at each transmission point. Driven by defensive, revenge, or strategic motives, outgroup-negative rumors in particular (e.g., Employee: "They say this new CEO specializes in savage layoffs," Manager: "I heard about an employee who falsified records," Engineer: "Marketing bribed the vendor to get the Johnson account!"), because of their corrosive effects on organizational trust, deserve special mention. When relationship- and self-oriented motives are ascendant over concerns for fact-finding, transmitters may be especially likely to spread such rumors within rather than between distinct clusters (e.g., management vs. employees, marketing vs. engineering, home office vs. plant), especially in segregated, conflicted, uncertain, or threatening change contexts. The result is that each cluster tends to produce an echo chamber within which such rumors are repeatedly circulated, exaggerated, and increasingly believed, each supporting polarized divergent social perceptions (e.g., of the change; DiFonzo, 2011; DiFonzo et al., 2011).

Trust Trust is an expectation of the benign nature of another's actions (Rousseau et al., 1998). Trust affects rumor transmission, and also moderates the relational and motivational dynamics involved in rumor transmission during change. In the aforementioned longitudinal study of 
workers undergoing radical downsizing (DiFonzo and Bordia, 2007a, ch. 8; cf. DiFonzo and Bordia, 1998), trust moderated the relationships between uncertainty and rumor transmission, and also between anxiety and rumor transmission: employees with high levels of trust in management tended to spread rumors when either anxious or uncertain, whereas low trust employees spread rumors regardless of anxiety or uncertainty. This is evidence that for high trust employees, fact-finding motivation was ascendant; for low trust employees, relationship- or self-oriented aims dominated. Open-ended commentary indicated that revenge motivation due to psychological contract breach figured largely in employee sentiment, as the nature of the change was drastic, threatening, and unilateral. Of course, trust is also an especially interesting non-linear variable because of its reciprocal relationship with rumor; we found evidence that repeatedly hearing negative rumors over time predicted greater distrust above and beyond previous levels of distrust.

\section{Implications of the motivational approach for understanding rumor accuracy and the management of rumors during change}

In this final section, we outline two implications of the motivational approach to understanding rumor spread. The first implication refers to how motivations affect the accuracy of rumors that arise from the collective response to organizational change. Second, we note the implications of the motivational approach for the management of rumors during change.

Rumor accuracy Though rumors have a reputation for being false (DiFonzo and Bordia, 1997), they may of course turn out to be true; thus rumors differ according to their degree of accuracy or the extent to which they correspond with reality (DiFonzo, 2010). Employees tend to be very good at ferreting out the facts when so motivated and when they have the capacity to do so (DiFonzo and Bordia, 2007a, ch. 6; Hellweg, 1987). Perhaps not surprisingly, fact-finding motivation results in greater rumor accuracy (Shibutani, 1966); relationship- and self-oriented motivations are less likely to result in accurate rumors (DiFonzo, 2010; cf., Buckner, 1965). In organizations, it appears that these two conditions are often present. With regard to motivation, the topics of internal organizational rumors typically include important changes that will affect employee job security and quality, the nature of the work itself, organizational direction and survival, and position within the organization (DiFonzo and Bordia, 2000; Hirschhorn, 1983); workers therefore want the facts in spite of any relationship- or self-oriented difficulties those facts entail. When motivated 
by fact-finding, the rumor spreader is more likely to acknowledge evidentiary lack with prefatory phrases such as "this may or may not be true..." or "I am not sure about this, but I have heard. .." and may seek additional information "have you heard this too?" or "is this true?" (Bordia and DiFonzo, 2004). When motivated by relationship- or self-oriented motives, the rumor may be spread as though it were news or fact, for example, "Our department is targeted for staff reduction." Spreading fallacy as though it were fact may be unintentional on the part of the teller, or it may be an element of a carefully orchestrated misinformation campaign for considered strategic purposes (DiFonzo and Bordia, 2007b).

Rumor management implications Rumors are difficult to control once they have begun to spread. The difficulty in part stems from the fact that beliefs, once formed, are notoriously difficult to change. Belief in a rumor is positively related to the number of times the rumor is heard (Rosnow, 1991). The longer a rumor is in circulation, the more it is likely to be heard and believed and the more difficult it will be to counter the rumor. Elsewhere we have provided detailed guidelines on how to combat harmful rumors (DiFonzo and Bordia, 2007a, ch. 9; DiFonzo, Bordia, and Rosnow, 1994). In essence, when confronted with a false and damaging rumor, it is important to rebut it forcefully via a credible and trustworthy source, using clear evidence countering the false allegations. However, fighting rumors can cost change managers valuable time and resources. Therefore, rumor prevention is clearly preferable to rumor combat. The motivational framework presented here can inform rumor prevention prevention efforts should strive to minimize uncertainty and threat to feelings of belongingness and self-esteem.

A great deal has been written about the management of uncertainty during change (Bordia et al., 2004; DiFonzo and Bordia, 1997; Schweiger and DeNisi, 1991). Timely and accurate information and participation in change-related decision making reduces uncertainty and enhances employees' sense of control over their work circumstances. However, from a change manager's perspective, this is sometimes easier said than done. The managers may themselves not have all the information and environmental uncertainty may make it difficult to commit to and communicate definitive future plans of action to employees. Our survey of highly experienced corporate communication professionals suggested that strategies that structure uncertainty are useful in such circumstances (DiFonzo and Bordia, 2002a). Rather than the unrealistic goal of eliminating uncertainty, these strategies aim to put boundaries on the types of issues that employees may be uncertain about (as opposed to allowing free-ranging uncertainty); one way this is achieved during organizational 
change is by clarifying the process and procedures by which upcoming changes will be decided and decisions made. These strategies are also aimed at addressing perceptions of procedural justice. As noted by research in organizational justice, if employees are confident about the fairness of procedures used, they are more likely to accept the outcome of the change process (Schaubroeck, May, and Brown, 1994).

Given that relationship- and self-oriented motivations also play a part in rumor spread, rumor prevention strategies need to address threats to feelings of belongingness and self-esteem of employees. Rumors are likely to circulate in groups of employees that share political or structural allegiance and some rumors (such as those that derogate senior managers) are unlikely to cross into communication networks shared by managers. Co-opting the support of employees from a range of diverse networks across the organization will assist in identifying threat perceptions that might lead to rumors. Finally, rumor prevention strategies need to address threats to self-esteem. Strategies that enhance perceptions of procedural justice will in turn signal to employees that they are valued members of the organization (Tyler et al., 1996). Literatures on readiness for change (Armenakis et al., 1993) and organization-based self-esteem (Pierce and Gardner, 2004) provide guidelines on how to create more positive reactions to change (see also Chapter 5 in this volume): managers should highlight employee skills, capabilities, and past contributions to the organization and remind employees of past instances of successful innovation and changes in the organization to enhance feelings of self-efficacy in dealing with the change.

\section{References}

Åckerström, M. (1988), “The social construction of snitches," Deviant Behavior, 9, 155-167.

Adams, J. S. (1965), "Inequity in social exchange," in L. Berkowitz (ed.), Advances in Experimental Social Psychology (New York: Academic Press), vol. II, 267-296.

Alicke M. D. and C. Sedikides (2009), "Self-enhancement and self-protection: What they are and what they do," European Review of Social Psychology, 20, 1-48.

Allport G. W. and L. J. Postman (1947), The Psychology of Rumor (New York: Holt, Rinehart \& Winston).

Armenakis, A. A., S. G. Harris, and K. W. Mossholder (1993), "Creating readiness for organizational change," Human Relations, 46, 681-703.

Ashforth B. E. and F. Mael (1989), "Social identity theory and the organization," Academy of Management Review, 14, 20-39.

Bartunek, J. M., D. M. Rousseau, J.W. Rudolph, and J.A. DePalma (2006), "On the receiving end: Sensemaking, emotion, and assessments of an organizational change initiated by others," Fournal of Applied Behavioral Science, 42, 182-206. 
Batson, C., N. Ahmad, and E. Stocks (2011), "Four forms of prosocial motivation: Egoism, altruism, collectivism, and principlism," in David Dunning (ed.), Social Motivation (New York: Psychology Press), 103-126.

Baumeister, R. F., E. Bratslavsky, C. Finkenauer, and K. D. Vohs (2001), "Bad is stronger than good," Review of General Psychology, 5, 323-370.

Baumeister, R. F. and S. Hastings (1997), "Distortions of collective memory," in J. W. Pennebaker, D. Paez, and B. Rimé (eds.), Collective Memory of Political Events (Mahwah, NJ: Lawrence Erlbaum Associates), 277-293.

Baumeister, R.F. and M.R. Leary (1995), "The need to belong: Desire for interpersonal attachments as a fundamental human motivation," Psychological Bulletin, 117, 497-529.

Baumeister, R. F., L. Smart, and J. Boden (1996), "Relation of threatened egotism to violence and aggression: The dark side of high self-esteem," Psychological Review, 103, 5-33.

Bluedorn, A. C. (1982), "A unified model of turnover from organizations," Human Relations, 35, 135-153.

Bordia, P. and N. DiFonzo (2002), "When social psychology became less social: Prasad and the history of rumor research," Asian fournal of Social Psychology, 5, 49-61.

(2004), "Problem solving in social interactions on the Internet: Rumor as social cognition," Social Psychology Quarterly, 67, 33-49.

(2005), "Psychological motivations in rumor spread," in G. A. Fine, C. Heath, and V. Campion-Vincent (eds.), Rumor Mills: The Social Impact of Rumor and Legend (New York: Aldine Press), 87-101.

Bordia, P., E. Hobman, E. Jones, C. Gallois, and V. Callan (2004), "Uncertainty during organizational change: Types, consequences, and management strategies," Fournal of Business and Psychology, 18, 507-532.

Bordia, P., E. Jones, C. Gallois, V. Callan, and N. DiFonzo (2006), “Management are aliens! Rumors and stress during organizational change," Group and Organization Management, 31, 601-621.

Bordia, P., S. L. D. Restubog, K. Kiazad, N. DiFonzo, and N. Stenson (2011), "Rumor as revenge in the workplace," manuscript.

Bordia, P., S. L. Restubog, and R. L. Tang (2008), "When employees strike back: Investigating mediating mechanisms between psychological contract breach and workplace deviance," Fournal of Applied Psychology, 93, $1104-1117$.

Brewer, M. B. (2003), Intergroup Relations (Philadelphia, PA: Open University Press).

Buckner, H. T. (1965), “A theory of rumor transmission," Public Opinion Quarterly, 29, 54-70.

Caplow, T. (1947), "Rumors in war," Social Forces, 25, 298-302.

Chusmir, L. H. (1986), "Personalized vs. socialized power needs among working men and women," Human Relations, 39, 149-159.

Cialdini R. B. and M. R. Trost (1998), "Social influence: Social norms, conformity, and compliance," in D. T. Gilbert, S. T. Fiske, and G. Lindzey (eds.), The Handbook of Social Psychology (4th ed., Boston, MA: McGraw-Hill), 151-192. 
DiFonzo, N. (2008), The Watercooler Effect: A Psychologist Explores the Extraordinary Power of Rumors (New York: Avery, Penguin).

(2010), "Ferreting facts or fashioning fallacies? Factors in rumor accuracy," Social and Personality Compass, 4, 1124-1137.

(2011), "The echo-chamber effect," New York Times, April 21 (retrieved April 21, 2011 , from www.nytimes.com/roomfordebate/2011/04/21/barack-obama-andthe-psychology-of-the-birther-myth/the-echo-chamber-effect).

DiFonzo, N. and P. Bordia (1997), "Rumor and prediction: Making sense (but losing dollars) in the stock market," Organizational Behavior and Human Decision Processes, 71, 329-353.

(1998), "A tale of two corporations: Managing uncertainty during organizational change," Human Resource Management, 37, 295-303.

(2000), "How top PR professionals handle hearsay: Corporate rumors, their effects, and strategies to manage them," Public Relations Review, 26, 173-190.

(2002a), "Corporate rumor activity, belief, and accuracy," Public Relations Review, 150, 1-19.

(2002b), "Rumors and stable-cause attribution in prediction and behavior," Organizational Behavior and Human Decision Processes, 88, 785-800.

(2006), "Rumor in organizational contexts," in D. A. Hantula (ed.), Advances in Psychology: A Tribute to Ralph L. Rosnow (Mahwah, NJ: Lawrence Erlbaum Associates), 249-274.

(2007a), Rumor Psychology: Social and Organizational Approaches (Washington, DC: American Psychological Association).

(2007b), "Rumors influence: Toward a dynamic social impact theory of rumor," in A. R. Pratkanis (ed.), The Science of Social Influence: Advances and Future Progress (Philadelphia, PA: Psychology Press), 271-296.

DiFonzo, N., P. Bordia, and R.L. Rosnow (1994), "Reining in rumors," Organizational Dynamics, 23, 47-62.

DiFonzo, N., M. J. Bourgeois, J. Suls, C. Homan, S. Brougher, A. J. Younge, and N. Schwab (MS in submission, 2011), "I heard that Democrats abuse drugs and Republicans are racist: Network clustering and group segregation effects on defensive and non-defensive rumor belief polarization and selforganization."

DiFonzo, N., N. Robinson, J. Suls, and C. Rini (2012), "Rumors about cancer: Content, sources, coping, transmission, and belief," fournal of Health Communication: International Perspectives, 17, 1099-1115.

Elsbach, K. D. and R. M. Kramer (1996), “Members' response to organizational identity threats: Encountering and countering the Business Week rankings," Administrative Science Quarterly, 41, 442-476.

Festinger, L. (1957), A Theory of Cognitive Dissonance (Evanston, IL: Row, Peterson).

Festinger, L., D. Cartwright, K. Barber, J. Fleischl, J. Gottsdanker, A. Keysen, and G. Leavitt (1948), "A study of rumor: Its origin and spread," Human Relations, 1, 464-485.

Fine, G. A. and N. DiFonzo (2011), "Uncertain knowledge," Contexts, 10, 16-21. Fiske, S. T. (2004), Social Beings: A Core Motives Approach to Social Psychology (Hoboken, NJ: Wiley). 
Ford, J. D. and L. W. Ford (1995), "The role of conversations in producing intentional change in organizations," Academy of Management Review, 20, 541-570.

Ford, J. D., L. W. Ford, and R. T. McNamara (2002), "Resistance and the background conversations of change," Fournal of Organizational Change Management, $15,105-121$.

Fugate, M., G. E. Prussia, and A. J. Kinicki (2012), "Managing employee withdrawal during organizational change: The role of threat appraisal," fournal of Management, 38, 890-914.

Grandey, A. A. and R. Cropanzano (1999), "The conservation of resources model applied to work-family conflict and strain," Fournal of Vocational Behavior, 54, 350-370.

Grice, H. P. (1975), "Logic and conversation: The William James Lectures," in P. Cole and J. L. Morgan (eds.), Syntax and Semantics (New York: Academic Press), vol. III, 41-58.

Heath, C. (1996), "Do people prefer to pass along good or bad news? Valence and relevance of news as predictors of transmission propensity," Organizational Behavior and Human Decision Processes, 68, 79-94.

Hellweg, S. A. (1987), "Organizational grapevines," in B. Dervin and M. J. Voigt, Progress in Communication Sciences (Norwood, NJ: Ablex), vol. VIII, 213-230.

Hirschhorn, L. (1983), Cutting Back: Retrenchment and Redevelopment of Human and Community Services (San Francisco, CA: Jossey-Bass).

Hobfoll, S.E. (2002), "Social and psychological resources and adaptation," Review of General Psychology, 6, 307-324.

Janis, I. L. (1972), Victims of Groupthink: A Psychological Study of Foreign-Policy Decisions and Fiascoes (Boston, MA: Houghton Mifflin).

Jimmieson, N. L., D. J. Terry, and V. J. Callan (2004), “A longitudinal study of employee adaptation to organizational change: The role of change-related information and change-related self-efficacy," Fournal of Occupational Health Psychology, 9, 11-27.

Jones, R. A., N. L. Jimmieson, and A. Griffiths (2005), "The impact of organizational culture and reshaping capabilities on change implementation success: The mediating role of readiness for change," fournal of Management Studies, 42, 361-386.

Kamins, M. A., V.S. Folkes, and L. Perner (1997), "Consumer responses to rumors: Good news, bad news," fournal of Consumer Psychology, 6, 165-187.

Kahneman, D. and A. Tversky (1979), "Prospect theory: An analysis of decision under risk," Econometrica, 47, 263-291.

Kapferer, J. N. (1990), Rumors: Uses, Interpretations, and Images (trans. B. Fink) (New Brunswick, NJ: Transaction), 217.

Knapp, R. H. (1944), “A psychology of rumor,” Public Opinion Quarterly, 8, 22-27.

Leary, M.R. (1995), Self-presentation: Impression Management and Interpersonal Behavior (Boulder, CO: Westview).

Lewin, K. (1951), Field Theory in Social Science (New York: Harper \& Row).

Lyons, A. and Y. Kashima (2006), "Maintaining stereotypes in communication: Investigating memory biases and coherence-seeking in storytelling," Asian Fournal of Social Psychology, 9, 59-71. 
McClelland, D.C. and D. Burnham (1976), "Power is the great motivator," Harvard Business Review, 54, 100-110.

Moorman, R. H. (1991), "Relationship between organizational justice and behaviors: Do fairness perceptions influence employee citizenship?," Fournal of Applied Psychology, 76, 845-855.

Pierce, J. L. and D. G. Gardner (2004), "Self-esteem within the work and organizational context: A review of organization-based self-esteem literature," Fournal of Management, 30, 591-622.

Pinder, C. C. (1984), Work Motivation. Theory, Issues, and Applications (New York: Harper Collins).

Prasad, J. (1950), "A comparative study of rumours and reports in earthquakes," British fournal of Psychology, 41, 129-144.

Pratkanis, A. R. and E. Aronson (2001), Age of Propaganda: The Everyday Use and Abuse of Persuasion (rev. ed., New York: W. H. Freeman).

Rothbaum, F., J. R. Weisz, and S.S. Snyder (1982), "Changing the world and changing the self: A two-process model of perceived control," fournal of Personality and Social Psychology, 42, 5-37.

Rimer, S. (1992), "American dream put on hold at car plant doomed to shut," New York Times, September 7, 1, 40.

Rogers, E. M. and R. Agarwala-Rogers (1976), Communication in Organizations (New York: Free Press).

Rosnow, R. L. (1991), "Inside rumor: A personal journey," American Psychologist, 46, 484-496.

Ross, J. and B. M. Staw (1993), "Organizational escalation and exit: Lessons from the Shoreham Nuclear Power Plant," Academy of Management Fournal, 36, 701-732.

Ruscher, J. B. (2001), Prejudiced Communication: A Social Psychological Perspective (New York: Guilford Press).

Rousseau, D. M., S. B. Sitkin, R. S. Burt, and C. Camerer (1998), "Not different after all: A cross-discipline view of trust," Academy of Management Review, 23, 393-404.

Salancik, G. R. and J. Pfeffer (1978), "A social information processing approach to job attitudes and task design," Administrative Science Quarterly, 23, 224-253.

Schachter, S. and H. Burdick (1955), "A field experiment on rumor transmission and distortion," Fournal of Abnormal and Social Psychology, 50, 363-371.

Schaubroeck, J., D. R. May, and F. W. Brown (1994), "Procedural justice explanations and employee reactions to economic hardship: A field experiment," Fournal of Applied Psychology, 79, 455-460.

Schein, E. H. (1996), "Kurt Lewin's change theory in the field and in the classroom: Notes toward a model of managed learning," Systems Practice, 9, 27-47.

Schweiger, D. M. and A.S. DeNisi (1991), "Communication with employees following a merger: A longitudinal field experiment," Academy of Management fournal, 34, 110-135.

Scott, J. P. (2000), Social Network Analysis: A Handbook (London: Sage).

Shibutani, T. (1966), Improvised News: A Sociological Study of Rumor (Indianapolis, IN: Bobbs-Merrill). 
Staw, B.M. (1981), "The escalation of commitment to a course of action," Academy of Management Review, 6, 577-587.

Tesser, A. and S. Rosen (1975), "The reluctance to transmit bad news," in L. Berkowitz (ed.), Advances in Experimental Social Psychology (New York: Academic Press), vol. XVIII, 193-232.

Turner, R. H. and L. M. Killian (1972), Collective Behavior (2nd ed., Englewood Cliffs, NJ: Prentice-Hall).

Tyler, T., P. Degoey, and H. Smith (1996), "Understanding why the justice of group procedures matters: A test of the psychological dynamics of the groupvalue model," Fournal of Personality and Social Psychology, 70, 913-930.

Wasserman, S. and K. Faust (1994), Social Network Analysis: Methods and Applications (Cambridge University Press).

Weenig, M. W. H., A. C. W. J. Groenenboom, and H. A. M. Wilke (2001), "Bad news transmission as a function of the definitiveness of consequences and the relationship between communicator and recipient," Fournal of Personality and Social Psychology, 80, 449-461.

Weick, K. E. and R. E. Quinn (1999), “Organizational change and development," Annual Review of Psychology, 50, 361-386.

Wood, W. (2000), "Attitude change: Persuasion and social influence," Annual Review of Psychology, 51, 539-570. 